January 1996

\title{
Treatment practices for degedege, a locally recognized febrile illness, and implications for strategies to decrease mortality from severe malaria in Bagamoyo District, Tanzania
}

\author{
A.M. Makemba \\ Bagamoyo Bed Net Project \\ P.J. Winch \\ Muhimbili University College of Health Sciences \\ V.M. Makame \\ Bagamoyo Bed Net Project \\ G.L. Mehl \\ Johns Hopkins University \\ Zul Premji \\ Aga Khan University, zul.premji@aku.edu \\ See next page for additional authors
}

Follow this and additional works at: http://ecommons.aku.edu/eastafrica_fhs_mc_pathol

Part of the Pathology Commons

\section{Recommended Citation}

Makemba, A., Winch, P., Makame, V., Mehl, G., Premji, Z., Minjas, J., Shiff, C. (1996). Treatment practices for degedege, a locally recognized febrile illness, and implications for strategies to decrease mortality from severe malaria in Bagamoyo District, Tanzania. Tropical Medicine and International Health, 1(3), 305-313.

Available at: http://ecommons.aku.edu/eastafrica_fhs_mc_pathol/95 
Authors

A.M. Makemba, P.J. Winch, V.M. Makame, G.L. Mehl, Zul Premji, J.N. Minjas, and C.J. Shiff 


\title{
Treatment practices for degedege, a locally recognized febrile illness, and implications for strategies to decrease mortality from severe malaria in Bagamoyo District, Tanzania
}

\author{
A. M. Makemba', P. J. Winch'1,4, V. M. Makame', G. L. Mehl', Z. Premji',2 , J. N. Minjas ${ }^{1,2}$ and \\ C. J. Shiff',3 \\ I Bagamoyo Bed Net Project and \\ ${ }^{2}$ Mubimbili University College of Health Sciences, PO Box 650r I, Dar es Salaam, Tanzania \\ 3 Department of Molecular Microbiology and Immunology and \\ ${ }_{4}$ Center for International Community-Based Health Research, Department of International Health, The Jobns Hopkins \\ University, School of Hygiene and Public Health, 6I5 North Wolfe Street, Baltimore, MD 2 I205, USA
}

\begin{abstract}
Summary Malaria remains one of the chief causes of mortality among young children in sub-Saharan Africa. Verbal autopsies for cases of childhood mortality in Bagamoyo District, Tanzania demonstrated that degedege, a locally defined illness of children characterized by fever and convulsions, is frequently treated by traditional healers. To investigate this further, an ethnographic study was carried out in one village that included in-depth interviews with $\mathrm{r} 4$ traditional healers and 3 focus groups with parents. Parents and traditional healers were unanimous in their conviction that degedege requires traditional treatments, at least initially, and that these treatments are effective. While traditional healers do refer cases that are not improving to the District Hospital, this frequently occurs late in the course of the illness, after one or more stages of traditional treatments. The prognosis will thus be poor for those children who are suffering from severe malaria. Consideration should be given to enlisting the support of traditional healers in efforts to improve treatment for severe malaria, including teaching them how to distinguish febrile convulsions from cases of severe malaria.
\end{abstract}

keywords traditional healers, malaria, mortality, ethnomedicine

correspondence Dr P. J. Winch, Center for International Community-Based Health Research, Department of International Health, The Johns Hopkins University, School of Hygiene and Public Health, 6I 5 North Wolfe Street, Baltimore, MD 2 I 205, USA

\section{Introduction}

Malaria remains one of the chief causes of mortality among young children in sub-Saharan Africa.

Greenwood (I990) has estimated that as many as half a million children die of malaria each year in Africa. Studies of mortality in The Gambia have documented rates of 6.3 per 1000 per year in infants and 10.7 per rooo per year in children aged $\mathrm{I}-4$ years (Greenwood et al. I987).

One of two clinical syndromes is usually associated with mortality from malaria in children: severe anaemia or cerebral malaria. The proportion of deaths attributable to either syndrome varies from one area to another. For example, in a recent paper Snow et al. (1994) describe how in an area of 
A. M. Makemba et ol. Treatment practices for degedege in Bagamoyo District, Tanzania

Table I Results of verbal autopsies on non-accidental, non-perinatal deaths among children under 5 years of age in Bagamoyo District, Tanzania, I992-1994

\begin{tabular}{|c|c|c|c|c|}
\hline Treatments taken & $\begin{array}{l}\text { All deaths } \\
\text { (non-accidental, } \\
\text { non-perinatal) }\end{array}$ & $\begin{array}{l}\text { Deaths at some } \\
\text { point after acute } \\
\text { onset of fever }\end{array}$ & $\begin{array}{l}\text { Deaths in } \\
\text { children with } \\
\text { degedege }\end{array}$ & $\begin{array}{l}\text { Acute onset of } \\
\text { fever and } \\
\text { degedege present }\end{array}$ \\
\hline Modern only (drugs, clinic) & 49 & 32 & 7 & 5 \\
\hline Traditional only & IO & 7 & 5 & 4 \\
\hline Modern and traditional & 26 & I7 & II & I I \\
\hline No treatments & 9 & 4 & 3 & 2 \\
\hline $\begin{array}{l}\text { Number }(\%) \text { receiving } \\
\text { traditional treatments }\end{array}$ & $36 / 94(38)$ & $24 / 60(40)$ & $16 / 26(62)$ & $15 / 22(68)$ \\
\hline Total & 94 & 60 & 26 & 22 \\
\hline
\end{tabular}

central Tanzania with very intense transmission, deaths usually occur from severe anaemia among children less than I year of age, while in coastal Kenya, where transmission is far less intense, deaths more commonly occur from cerebral malaria in children 2-4 years of age.

A number of factors contribute to mortality from malaria, including lack of transport in rural areas, poor drug supply in health care facilities, drug resistance and lack of familiarity on the part of health workers with current protocols for the treatment of severe malaria. Nevertheless, improving access to appropriate treatment may not have an impact on mortality from malaria: parents or caretakers of sick children may delay seeking treatment from the formal health care system or may avoid this system altogether in favour of traditional healers.

\section{Mortality in the study area}

This study forms one part of a larger intervention trial of insecticide impregnated mosquito nets being conducted in 13 villages in Bagamoyo District on the coastal plain of Tanzania, $50 \mathrm{~km}$ north of the capital, Dar es Salaam (Makemba et al. 1995). An epidemiological surveillance system to monitor mortality among children was established as part of the plan to evaluate the impact of the insecticide impregnated mosquito nets. Community health workers document all cases of childhood mortality, and verbal autopsies are conducted which are then coded independently by two physicians. These results are reported in detail elsewhere (Premji et al. unpublished). The infant mortality rate was 1 I 5.3 per I0oo live births in 1992 , and 96.5 per Iooo live births in 1993 . The child mortality rate (ages $1-4$ ) was 7.8 per 1000 years at risk in $\mathbf{I} 992$, and II.I in I993.

Traditional practitioners are a common source of treatment in the area, and had seen many of the children who died and were detected by the surveillance system sometime during their course of treatment. They were a particularly common source of treatment for cases of degedege. Within the formal health system this term is used to denote convulsions, but it has a wider range of meanings among the local population, as described below. Between April 1992 and March 1994, I39 verbal autopsies were performed. If still births, deaths during the first few days of life and accidental deaths are excluded, for which treatment could not have been sought, a total of 94 verbal autopsies remain. As shown in Table I, in 36 (or $38 \%$ ) of these cases, traditional treatments had been used at some time in the course of the illness. For cases involving degedege, the proportion is much higher with I 6 of 26 children, or $62 \%$, having received traditional treatments. The odds of traditional treatments having been administered is 3.84 times higher (CI I.35, II.08, $\chi^{2}=6.91, P=0.009$ ) in cases were degedege had been present, compared to those where it was absent. These findings are consistent with a number of other studies. For example, De Francisco et al. (1994), in a study of childhood mortality in The Gambia, found that traditional healers were consulted frequently, even in villages where a community health worker was present, and 
A. M. Makemba et al. Treatment practices for degedege in Bagamoyo District, Tanzania

that they were consulted more frequently for specific conditions.

\section{Objectives of the study}

Based on the above results from the surveillance system for childhood mortality, objectives were formulated for a pilot qualitative research study on the role of traditional healers in the treatment of degedege. The objectives of this study were:

(I) To examine perceptions of traditional healers and parents regarding the causes, symptoms and treatments for degedege.

(2) To investigate why people perceive that treatments administered by traditional healers are effective for degedege.

(3) To define possible intervention strategies for promoting timely and appropriate treatment for degedege.

\section{Materials and methods}

Study site and ethnic groups

The predominant ethnic groups in Bagamoyo District, Tanzania are the Zaramo (Beidelman 1967; Swantz 1970), Kwere (Beidelman 1967) and Swahili (Prins 1961; Middleton 1992). Since independence, the establishment of schools, colleges, health facilities and the availability of land have continued to attract people from all parts of Tanzania. Swahili (kiswabili) is the principal language used, although Zaramo is also common. The population is mostly Muslim, although many migrants from the interior are Christian. One out of the $\mathrm{I} 3$ villages in the larger mosquito net intervention trial was chosen for intensive data collection in the present study because it was known to have a number of traditional healers who had expressed their willingness to participate in the study.

\section{Methods}

Field-workers had been in contact with people from this village for 3 years before this exploratory study began. During the study, two social scientists lived for 2 weeks in the village, observing treatment practices and conducting key informant-type interviews.
Fourteen practitioners were identified, of whom I I were waganga (singular mganga) or practitioners whose primary work was the diagnosis and treatment of illnesses, and 3 were traditional midwives. The $\mathrm{r}_{4}$ practitioners ranged in age from 55 to $8 \mathrm{I}$, with the exception of one man aged 35 , and represent all the individuals who treat degedege in the village. Interviews with traditional healers each lasted at least 2 hours. Some were conducted over a period of $\mathrm{r}-2$ days because the healers were interrupted by visits from patients. Expanded field notes with explanations and observations of treatment practices were written up after each interview. The interviews concerned the characteristics of each traditional healer's practice, as well as his or her knowledge of the symptoms, cause and treatment of those illnesses s/he commonly treats, especially degedege. Three focus groups were conducted with parents who had taken their children for consultation with traditional healers in the village, in addition to in-depth interviews.

\section{Results}

The illness degedege

The word degedege was familiar to all people interviewed for this study. Within the formal health system, degedege is used as a translation for convulsions in children, especially febrile convulsions. As such, it is more a sign of underlying disease than a disease itself. Although people seem to understand the meaning given to the word by health workers, their own use of the word is to denote an illness with its own specific cause, symptoms and treatments.

In key informant interviews with parents, degedege was said to be recognized by the sudden onset of severe fever, trembling and/or stiffness of the limbs, frothing at the mouth, babbling incomprehensibly (which is sometimes interpreted as speaking foreign languages) and a high mortality rate. This illness is greatly feared, especially because of its sudden onset.

A few parents stated that degedege is caused by malaria fever going to the brain, and many were unsure of the cause. Others explained that it is due to a spirit attacking the child. Several respondents 
A. M. Makemba et al. Treatment practices for degedege in Bagamoyo District, Tanzania

gave a detailed description of how the spirit attacks. The spirit is a coastal one, in particular the spirit named ibilisi. This spirit assumes the form of a bird and flies over houses, inflicting degedege on adults and children below.

In focus group discussions with parents, the treatment of degedege was discussed in further detail. Parents stated that the decision to take a child to a traditional practitioner, a village health worker or a dispensary depends on a number of factors, particularly the age and experience of the mother and opinion of the elders. In a typical sequence of events, a child with fever is first cared for in the home for I-3 days. At this point, parents assume that the child has an ordinary fever (boma ya kawaida) that will go away on its own. If the child develops symptoms of degedege such as shaking, rigid body and eyes turning up, treatment is sought outside the home. If the parents of the child are older and more experienced, they may decide what to do on their own. If the parents are young and inexperienced, they seek advice from an elder who 'has eyes to see'. If the husband is not at home, the mother will need to take the child to the husband's parents, a process that can take much time if they do not live nearby. If the elders feel the child has degedege, parents in all three focus groups stated that a recommendation to consult a traditional healer would be made. A specific traditional healer is recommended, based on his or her reputation for being effective in treating degedege.

The traditional practitioners themselves may not be consulted until after the illness has continued for several days, as one father explained:

'My child started with everyday fever (homa ya kawaida) on the first and second days, but suddenly it became a disease (ugonjwa), the child was in big trouble, he had no strength, saliva was coming out of his mouth, he was vomiting, his eyes had turned up, and his ribs were squeezing together hard.'

At this point he went to an elder, who advised him to take the child to the traditional practitioner.

Parents in all 3 focus groups stated that if the child had degedege, s/he should not under any circumstances receive an injection because the child will die. Puncturing the skin allows spirits to come and remove all the blood from the child. This is one of the main reasons that hospital treatment is avoided for this illness. Once the degedege has first been treated and 'removed' by a traditional healer, it is felt beneficial to seek treatment at the hospital to replenish water and blood lost during traditional treatment.

\section{The practitioners and their methods of diagnosis}

The ${ }_{4} 4$ healers who were interviewed were of four different types:

(i) Traditional midwives. The three traditional midwives view the treatment of degedege as a side occupation that they have become involved in when grandchildren or children they have delivered in the past have been brought to them. All three are Zaramo, and range in age from 60 to 65 .

(ii) Most of the practitioners were herbalists (waganga wa mizizi), accounting for 9 out of the II waganga. The three midwives also administer herbal treatments, although they do not call themselves herbalists. The focus of the practice of the herbalists is the treatment of illnesses, including degedege. The practice itself is a part-time occupation, with the rest of their time devoted to the cultivation of crops such as rice and cassava.

(iii) The third type consists of specialists in spirit possession or exorcists (waganga wa mizimu, fundi wa kishenzi). Only one individual fell into this category. This practice can only be inherited, it cannot be learned by an outsider. Although the practitioner interviewed knows how to treat degedege, he did not view it as his area of specialization. His speciality is exorcism ceremonies (madogoli) for Kinyamkera, a female Zaramo spirit that lives in the forest and can cause severe illness in both adults and children.

(iv) The fourth type are the 'craftsmen of the book' (fundi wa kitabu) or specialists in medical diagnosis and treatment based on the Koran and other Islamic holy books. This specialization, unlike the others, is not inherited. Knowledge of Islamic medicine comes at a later age as a further step in the acquisition of Islamic knowledge. This practitioner, as well as another fundi wa kitabu who lives in a neighbouring village, learned their craft from a well known older man (sheikh). Only a small proportion of this practitioner's practice consisted in the diagnosis and 
A. M. Makemba et al. Treatment practices for degedege in Bagamoyo District, Tanzania

treatment of illnesses. More common reasons for consultation included desire for a promotion at work and resolution of inter-personal conflicts.

Diagnosis of the illness or personal problem by the traditional healer takes place in one of several ways. Some practitioners, including the midwives and many of the herbalists, base the diagnosis on the symptoms of the patient, and on the time of year in which the illness has occurred. Therapeutic actions depend on the diagnosis made. Other practitioners use methods of divination (ramli) that are not directly based on the condition of the patient. The first method is spirit divination, in which the practitioner allows himself to be possessed by a spirit. A second method of divination is called kibuluga. Shortly after the patient is brought to the practitioner, and without eliciting symptoms, s/he walks out of the house and writes words in the sand in an unknown language. S/he then interprets the words, which tell what the symptoms, diagnosis and treatment are for the patient. The third method of diagnosis is book divination (ramli ya kitabu) and is used by the 'craftsman of the book' or mganga wa $k i t a b u$. The practitioner notes the time the patient arrives, the name of the patient and the name of the patient's mother. He then makes calculations and looks in the book known as the satrikbabari, which will reveal the star under which the person is being controlled, and the nature of the problems associated with that star.

\section{Practitioners' descriptions of degedege}

Treatment of degedege was an important component of the practice of all of the practitioners interviewed. Degedege is viewed as an illness that traditional practitioners are uniquely qualified to treat. A role is seen for cosmopolitan medicine only after traditional treatments have been applied.

Practitioners vary in how they define degedege, in terms of the existence of different types, its relation to other serious illnesses affecting children and adults, its symptoms and its treatments. One herbalist described the two different types in this way: '... there is the big one and the small one. The big one is called bane, and its young brother is called mkulu hatambulwa (literally: the big one whose name is not mentioned). And this hatambulwa can be male or female'. He then went on to describe how he differentiates between the two: 'The bane, from my knowledge I know him by looking at how the patient is. If he has taken hold of an adult, he falls down, he urinates and defaecates and saliva comes out of his mouth. The male mkulu hatambulwa, he takes hold of a child, you see that his eyes have turned up, his pupils have disappeared, his arm and leg are pushing out on the side [the spirit] has reached. His ribs are pushing up, and saliva comes out of his mouth. [The female one], many say it is degedege, the child has a very hot body, ceases to breast-feed, the joints become loose and sometimes the body goes stiff'.

Most, but not all, of the practitioners agreed with the statement in the preceding paragraph that male and female types of degedege exist. Several practitioners mentioned that the male type affects the right side, and can be diagnosed by noting that the right arm and leg are moving more than the left. The female type affects the left side, and causes the limbs on the left side to move more. Commonly mentioned symptoms of degedege among the 14 practitioners were the eyes turning up ( $\left.\mathrm{I}_{\mathrm{I}} / \mathrm{I}_{4}\right)$, fever ( $\left.\mathrm{I}_{\mathrm{I}} / \mathrm{I}_{4}\right)$, body going stiff $\left(\mathrm{IO} / \mathrm{I}_{4}\right)$, looseness of the joints and shaking of the limbs $\left(7 / 1_{4}\right)$ and ribs pushing up (5/I4). Less commonly mentioned symptoms were shaking, refusing to breast-feed, yellowness of the eyes, saliva coming out of the mouth and weakness. Thus it can be seen that the symptoms of the various types of degedege are compatible with what medical personnel would diagnose as febrile convulsions, epilepsy, cerebral malaria, or meningitis.

There is much variation regarding the perceived cause of degedege. The word degedege itself literally means 'bird-bird'. Three of the practitioners stated that the illness is caused by a big, evil bird (dege) passing over the house where the child is sleeping. The child's eyes follow the path of the bird. If the bird passes from right to left, the child's eyes will also turn from right to left. In either situation, the child contracts degedege from the passing spirit. A further three practitioners attributed degedege to the cold wind and cloudy skies found during the rice harvest season in July. (Further details on perceptions of seasonality in this area can be found in Winch et al. 1994.) Two practitioners stated that degedege is a long-term consequence of the child 
A. M. Makemba et al. Treatment practices for degedege in Bagamoyo District, Tanzania

sucking on the umbilical cord during birth, thereby ingesting dirtiness. A further two said that the illness is caused by sorcery, and one attributed it to God. The 'craftsman of the book' stated that degedege is caused by a special spirit, Al-hamar al-miriih, that rides on the back of a horse and comes in the cold south wind that blows during the rice harvest season. This spirit also was said to live in big trees, and can attack children when they pass under one of these trees. Two of the herbalists stated that they do not know the cause of the illness.

\section{Treatments for degedege}

Treatments administered by the various practitioners vary in terms of the types of herbs or incantations used, the timing of the treatments, and the amount of time allowed for the treatment to act before the patient is referred to the hospital.

Several of the herbalists described a two-stage treatment for degedege. The aim of the first stage is to 'calm the child down' so that s/he ceases to convulse, the eyes are no longer turned up, and the child 'cheers up'. The first stage of treatment lasts as long as 3 days. One herbalist described the first stage as follows:

'Regarding treatment, there are two types, the initial one and then the one where you cook (for the patient). The initial one is to calm down (the patient), you go out into the bush to pick herbs, the leaves of mbembelule, when you return you grind them, soak them in cold water, squeeze out (the water), then you spray the water on the child's head, ears, eyes and entire body. The child urinates. You get more of this water and give it to him to drink. (The child) should only eat freshlycooked food'.

After symptomatic relief is obtained with the first stage, the second stage is carried out whose aim is to attack the cause of the illness, the degedege. The herbalist went on to describe the second stage in this way:

'When you finish with the treatment that you spray on the child for one or two days, if the child gets relief, you go and cook for him where two roads meet. You tell the father of the sick child to bring a chicken and a new [clay] cooking pot on that very day. You (the herbalist) now go into the bush to dig roots to cook for the patient. The drug itself is roots of the mkomalwiza tree, or mkilika by another name, and also the msepelela or mkoma misungu tree. While you are digging, you chant to the tree (asking it to help you cure the patient), another tree is gole, and (the fourth tree) is mjata or msosowana. When you get back home, you cut the root of each tree into small pieces and tie it into a bundle, so you end up with four different bundles. The chicken is then sacrificed, the feathers are plucked off, you make an incision down the centre of the body, the intestines are removed, then the (remaining) meat is cooked with the four bundles of roots. This medicine is cooked in a brand-new pot. The gravy is given to the patient to drink, and the meat is eaten without chewing on the bones. These drugs (the roots), the feathers, the (unchewed) bones, the intestines, are all put into the pot, a hole is dug right where the cooking took place, the whole pot is buried upside-down and a hole is made at the bottom of the pot. At this point the degedege is buried, it does not return again to the child, although sometimes the child still has some residual hospital fever (homa ya hospitali)'.

The other herbalists also follow the two-stage treatment procedure, although there is some variation regarding the types of roots that are used and the duration of each stage. Herbalists then recommend to the parents to take their child to the health centre where they can remove any residual symptoms of degedege (i.e. homa ya hospitali).

The 'craftsman of the book' (fundi wa kitabu) also employs a two-stage treatment, but he does not dig up roots in the bush. In the first stage, he mixes together in a bottle the gum of the asafoetida tree (mvije) that is sold in shops, a type of flour called halititi and vinegar, then sprays one quarter of a cup on the child, and places drops of the mixture on the child's lips, nostrils and ears, as well as giving the child one-quarter of a teaspoon of it to drink. He then rubs it all over the child's body. If the child improves, the parent is given some of the mixture to administer to the child over the next 2 days. If the fever continues after 3 days of this treatment, the 
A. M. Makemba et al. Treatment practices for degedege in Bagamoyo District, Tanzania

'craftsman of the book' either advises the parents to take the child to the hospital, as 'sometimes it may be that the child has mosquito fever (homa ya $m b u$ ), or administers a second stage of treatment. In this second stage, he writes an appropriate verse from a book called shamsi maarifa likubra inside a saucer using ink made with saffron, then he puts water in the saucer to dissolve the ink, and the patient drinks this water. The same verse is written on a white piece of paper, folded up and placed in an amulet (birizi) that the patient then wears as protection against future attacks of degedege.

\section{Referral of cases to the hospital}

The traditional practitioners all recognize that in some cases they should refer patients to the hospital. They view themselves as the ones who remove the 'core illness' caused by the spirit or evil bird that is called degedege. The role of the hospital is to resolve residual effects of the illness (the hospital fever) that remain after the core illness has been cured. One practitioner stated that, after his treatment, 'there are still problems, so you tell him (the patient) to go to the hospital because sometimes he does not have blood or water in his body, I do not have any expertise with that type of problem'.

Referral of patients to the hospital takes place only after the traditional practitioners have completed their treatments. As full administration of their treatments may require $3-7$ days, traditional practitioners may refer patients to the hospital as long as $4^{-8}$ days after the initial consultation.

\section{Discussion}

This paper has examined treatment practices for degedege in Bagamoyo District, Tanzania. Although biomedical personnel use the word as a translation for convulsion, in local use it is a distinct illness with its own set of symptoms, causes and treatments. This illness is of interest to us for two reasons. First, parents stated that it was present in a significant number of the cases of child mortality detected by a mortality surveillance system. Second, the symptoms of degedege, according to both parents and traditional healers, include convulsions, rigidity of the body, eyes rolling up, and alteration of consciousness.
Although it cannot be stated with certainty what biomedical diseases degedege corresponds to, the symptoms are compatible with febrile convulsions, severe and complicated malaria including cerebral malaria, severe pneumonia and meningitis. Arriving at definitive diagnoses for cases of degedege will be a focus for a future study. Among non-fatal cases, the majority are probably febrile convulsions, as these are relatively common in children. Among fatal cases severe malaria probably accounts for many, given that the combination of acute onset of fever and degedege was common, as shown in Table I. Study of treatment patterns for degedege is thus one way of learning how to decrease mortality from severe malaria.

This study has shown that traditional healers are seen as the most appropriate source of treatment for degedege, and they are perceived to be effective in treating it. Several reasons for this can be identified. (I) Traditional healers enjoy the respect of villagers, due to their older age, their many years of residence in the community, and the fact that they provide detailed descriptions regarding the causes of the illness and the steps that should be taken to treat it. They are a natural source of care for an illness that is frightening and of sudden onset.

(2) Traditional treatments for degedege have high empirical efficacy. Another way of saying this is people observe that the treatments cure the illness in most cases. One reason for this could be what Young (1979) has termed nosological fusion, meaning that people 'fail to distinguish what are, from the biomedical point of view, two or more discrete diseases'. In this case, people use the same word degedege to refer to both severe malaria and febrile convulsions. The latter are common, rarely fatal, and are made better through lowering the child's body temperature. Traditional treatments reported in this study such as spraying the sick child's body with a mixture of herbs would have an effect similar to the sponge baths given in hospitals. Traditional healers thus intervene and take credit for cases that would have resolved spontaneously.

(3) Hospital treatments have low empirical efficacy. It is difficult for parents to take their children to the District Hospital in Bagamoyo Town. When they do choose to go to the hospital, significant delay is almost always involved, due to difficulties in 


\section{A. M. Makemba et al. Treatment practices for degedege in Bagamoyo District, Tanzania}

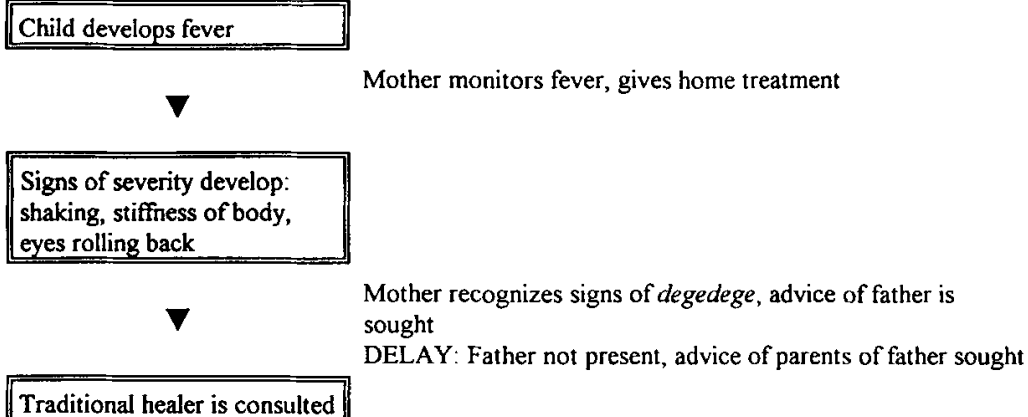

DELAY: Appropriate herbs need to be found in the forest

First stage of traditional treatment

DELAY: Appropriate herbs need to be found in the forest: DELAY: Parents must obtain a chicken and a new clay pot (May need to borrow money first)

Second stage of traditional treatment

DELAY: When degedege does not resolve, child may be
referred to another traditional healer
DELAY: Parents may have no means of transport to hospital
$\begin{aligned} & \text { Child brought to hospital or } \\ & \text { dispensary }\end{aligned}$

DELAY: Hospital does not have appropriate antimalarial drugs, intravenous fluids, and/or trained personnel

Child receives appropriate treatment for severe malaria

Figure I Potential sources of delay in obtaining intravenous treatment for a case of severe malaria transport, especially during the rainy season. If treatment for severe malaria is delayed, it is less likely to work, so parents come to associate hospital treatment with poor outcomes. In this study, parents were found to be unanimous in their conviction that treating degedege with an injection results in the death of the child.

An intervention to decrease mortality from severe malaria would need to try to deliver intravenous fluids and antimalarial drugs to the child early in the course of the illness. A prerequisite for such a strategy will be an adequate supply of intravenous fluids, i.v. equipment and trained personnel in hospitals and dispensaries. Once this is in place, cases of severe malaria need to be referred more rapidly to these facilities. As degedege appears often to correspond to severe malaria, and traditional healers are seen as the primary source of treatment for this illness, efforts to promote rapid referral of patients with severe malaria to hospitals and dispensaries must involve traditional healers.

This study identified a number of points where local treatment-seeking behaviour results in delay in appropriate clinic treatment. These are illustrated in Figure I, and described below. Treatment seeking begins with a mother recognizing the symptoms and signs of degedege as more serious than that of other illnesses. Assistance is sought from her husband or, if he is not available, from his parents. Based on previous experience with traditional healers, one is selected and sought for treatment. The traditional healer diagnoses the child's illness and begins the two-stage treatment regimen. In each stage, time is spent by the healer obtaining necessary roots and herbs, and by the caretakers seeking requested items such as a chicken or a new clay pot. Treatment is 
A. M. Makemba et al. Treatment practices for degedege in Bagamoyo District, Tanzania

conducted and the patient monitored for signs of improvement. At this point, if the child has not improved, the caretakers and child are referred to another traditional healer or the hospital. It is apparent that this process may delay necessary clinical attention for many days beyond the point when intravenous administration of antimalarial drugs and fluids should be instituted for severe malaria.

An intervention aimed at enhancing the ability of traditional healers to distinguish between degedege due to severe malaria and degedege due to febrile convulsions and to understand the importance of prompt referral of the former to a hospital or dispensary would be one way to improve treatment seeking for severe malaria. Green's (1994) work in several different African countries on sexually transmitted diseases and HIV prevention demonstrates the potential for successful collaboration with traditional healers in public health interventions. Although village health workers (VHWs) had an impact on mortality due to pneumonia in a previous programme in this area (Mtango \& Neuvians 1986), the fact that degedege is seen as a speciality of traditional healers makes it difficult for VHWs to have an impact on malaria related mortality.

The Tropical Diseases Research Programme of the World Health Organization is developing a 'Focused Ethnographic Study of Malaria', a community-based ethnographic study of childhood malaria whose purpose is "to improve our understanding of the way in which families perceive and respond to malaria and its signs and symptoms' (WHO-TDR I993). This protocol focuses on how parents make decisions about treatment for malaria. While a component of formative research on treatment seeking, we believe, based on this study, that decision-making patterns among traditional healers also need to be examined, and may be of greater importance programmatically than the patterns found in parents.

\section{References}

Beidelman TO (197x) The Kaguru: A Matrilineal People of East Africa. Holt, Rinehart \& Winston, New York. Beidelman TO (1967) The Matrilineal Peoples of Eastern Tanzania. International Africa Institute, London. p. I03.
De Francisco A, Armstrong Schellenberg J, Hall AJ et al. (I994) Comparisons of mortality between villages with and without Primary Health Care workers in Upper River Division, The Gambia. Journal of Tropical Medicine and Hygiene 97, 69-74.

Green EC (1994) AIDS and STDs in Africa-Bridging the Gap between Traditional Healing and Modern Medicine. Westview Press, Boulder, CO.

Greenwood BM (1990) Populations at risk. Parasitology Today 6, I 88 .

Greenwood BM, Bradley AK, Greenwood AM et al. (1987) Mortality and morbidity from malaria among children in a rural area of The Gambia, West Africa. Transactions of the Royal Society for Tropical Medicine and Hygiene 8I, 478-486.

Makemba M, Winch PJ, Kamazima SR et al. (1995) Implementation of a community-based system for the sale, distribution and insecticide impregnation of mosquito nets in Bagamoyo District, Tanzania. Health Policy and Planning 10, 50-59.

Middleton J (1992) The World of the Swahili: An African Mercantile Civilization. Yale University Press, New Haven, CT.

Mtango FDE \& Neuvians D (1986) Acute respiratory infections in children under five years. Control project in Bagamoyo District, Tanzania. Transactions of the Royal Society for Tropical Medicine and Hygiene 80, $85 \mathrm{I}-858$.

Prins AHJ (196i) The Swabili-speaking Peoples of Zanzibar and the East African Coast. International African Institute, London.

Snow RW, Bastos de Azevedo l, Lowe BS et al. (1994) Severe childhood malaria in two areas of markedly different falciparum transmission in East Africa. Acta Tropica 57, 289-300.

Swantz M-L (1970) Ritual and symbol in transitional Zaramo society: with special reference to women. Studia Missionalia Uppsaliensia r6, Gleerup-Lund, Uppsala.

WHO-TDR (1993) A Focused Ethnographic Study of Malaria. World Health Organization, Tropical Disease Research Programme. Draft, 9 December 1993.

Winch PJ, Makemba AM, Kamazima SR et al. (1994) Seasonal variation in the perceived risk of malaria: implications for the promotion of insecticide-impregnated bed nets. Social Science and Medicine 39(I), 63-75.

Young A (1979) The dimension of medical rationality: a problematic for the psychosocial study of medicine. In Towards a New Definition of Health (eds PI Ahmed \& GV Coelho), Plenum Press, New York. pp. 67-85. 